\title{
RESEARCH
}

Open Access

\section{COL1A1 polymorphism and neurological complications in pediatric acute lymphoblastic leukemia patients and their associations with altered bone mineral density}

Alaa A. Omran ${ }^{1}$, Rania S. Nageeb², Ghada S. Nageeb ${ }^{3}$, Manal A. Yosif ${ }^{3}$, Yassir A. Mohammad ${ }^{3}$, Alshimaa A. Ali ${ }^{4}$, Mervat Atfy ${ }^{4}$, Taghreed M. Azmy ${ }^{5}$ and Hanaa H. Elsaid ${ }^{1 *}$

\begin{abstract}
Background: Osteoporosis and neurological complications are consequences of acute lymphoblastic leukemia (ALL). Collagen type I alpha 1 gene (COL1A1) polymorphism is associated with osteoporosis. This study aimed to detect the COL1A1 polymorphism and the neurological complications in ALL patients and their association with decreased lumbar spine bone mineral density $\left(B M D^{L S}\right)$. This study included 100 pediatric ALL patients and 100 controls. All participants were subjected to laboratory assessment and assessment of BMD ${ }^{\mathrm{LS}}$ at the start of the study and 3 years later. COLIA1 genotyping was done once for all participants.

Results: At the start of the study, there was a significant decrease in osteocalcin (OC), alkaline phosphatase (ALP), and BMD"S levels in the patients. G/T variants and "T" alleles were significantly more detected in the patients (34\% and 35\% respectively); also, significant differences were detected between patients with polymorphism (G/T and T/ $\mathrm{T})$ and those without polymorphism $(\mathrm{G} / \mathrm{G})$ regarding $\mathrm{OC}, \mathrm{ALP}$, and $B \mathrm{MD}^{\mathrm{LS}}$. After 3 years, significant decrement in $B M D^{L S}, O C$, and ALP was detected in the patients. Twenty-four patients had neurological complications and seven patients had bone fractures. Those patients had significant decrement in BMD ${ }^{L S}, O C$, and ALP levels. As regards COLIA1 gene polymorphism, the GT and $\Pi$ variants were significantly detected in fractured patients, while there was no significant difference regarding GT and $\pi$ variants in the patients with neurological complications. $T$ allele, neurological complications, high-risk stratification, and age were significantly associated with decreased BMD ${ }^{\mathrm{LS}} . T$ allele was the most significant risk factor.

Conclusion: COLIA1 gene polymorphism, decreased $B M D^{L S}$, and neurological complications were significantly detected in pediatric ALL patients. COLIA1 gene polymorphism is a significant risk factor for decreased BMD ${ }^{L S}$ in pediatric ALL patients. There is no significant relation between COLIA1 gene polymorphism and the development of neurologic complications.
\end{abstract}

Keywords: Leukemia, Osteopenia, Genetics, Polymorphism, Neurological manifestations

\footnotetext{
* Correspondence: hanaahosny52@yahoo.com

'Department of Clinical Pathology, Faculty of Medicine, Zagazig University,

Zagazig, Egypt

Full list of author information is available at the end of the article
}

\section{Springer Open}

(c) The Author(s). 2020 Open Access This article is licensed under a Creative Commons Attribution 4.0 International License, which permits use, sharing, adaptation, distribution and reproduction in any medium or format, as long as you give appropriate credit to the original author(s) and the source, provide a link to the Creative Commons licence, and indicate if changes were made. The images or other third party material in this article are included in the article's Creative Commons licence, unless indicated otherwise in a credit line to the material. If material is not included in the article's Creative Commons licence and your intended use is not permitted by statutory regulation or exceeds the permitted use, you will need to obtain permission directly from the copyright holder. To view a copy of this licence, visit http://creativecommons.org/licenses/by/4.0/. 


\section{Background}

Osteoporosis is a frequent consequence in pediatric acute lymphoblastic leukemia (ALL) patients and neurological complications may be associated with low lumbar spine bone mineral density $\left(\mathrm{BMD}^{\mathrm{LS}}\right)$, as both $\mathrm{BMD}^{\mathrm{LS}}$ and neurological squeal among acute lymphoblastic leukemia survivors share common etiological factors (like exposure to methotrexate and cranial radiation) [1]. Determination of the risk factors for altered $\mathrm{BMD}^{\mathrm{LS}}$ in these patients may lead to appropriate interventions to reduce the incidence of morbidity, mortality, health care costs, pain, and the burden of care on the family members ultimately responsible for them. The collagen type I alpha 1 (COLIA1) gene is involved in the regulation of bone mass as it encodes type I collagen that is considered the major protein of bone matrix [2]. A polymorphism in the transcriptional control region of the COLIA1 gene results in alleles having a G-base of the Sp1 binding site. Those are defined as "G" alleles, while alleles with a T-base at the Sp1 binding site are defined as " $\mathrm{T}$ " alleles. Patients with " $\mathrm{T}$ " allele are suggested to have fractures and reduced $\mathrm{BMD}^{\mathrm{LS}}$ [3]. The $\mathrm{G} \rightarrow \mathrm{T}$ substitution in the Sp1 binding site of the COLIA1 gene is one of the polymorphisms that are associated with a low $\mathrm{BMD}^{\mathrm{LS}}[4]$. There is a high risk of fracture in relation to COLIA1 polymorphism. COLIAI genes have an important role in osteoporosis development [3]. Also, there is an association between the COL1A1 gene polymorphism and reduced arterial compliance that could be mediated through changes in collagen deposition and it may attribute to the development and progression of atherosclerosis and increased cardiovascular risk $[5,6]$. Previous studies have reported a significant impact of different genotypes of COLIA on neurological disorders [7, 8]. COLIA 2 could be a genetic risk factor for intracranial aneurysm and stroke. The COLAA1 gene mutation could be a genetic risk factor for variable neurological features, such as stroke, migraine, and seizures [9, 10]. Imaging modalities and treatment procedures have improved the prognosis however the frequency of neurological complications have also increased that are related to the acute lymphoblastic leukemia itself and/or to the treatment [11]. Treatment protocols of pediatric acute all involve multiple administrations of the neurotoxic chemotherapeutic drugs. Peripheral neuropathy is a well-known toxicity among those patients [12]. Moreover, lumbosacral radiculopathy after intrathecal chemotherapy is reported [11]. Furthermore, central neurotoxicity can result in multiple clinical manifestations, e.g., impaired consciousness, focal deficits, seizures, and headaches [13, 14]. To our knowledge, no previous study has detected the relation between the collagen type I alpha 1 gene (COL1A1) polymorphism and the neurological complications in pediatric acute lymphoblastic leukemia (ALL) patients and their association with altered lumbar spine bone mineral density $\left(\mathrm{BMD}^{\mathrm{LS}}\right)$. So, this study aimed to detect the collagen type I alpha 1 gene polymorphism and the neurological complications in the pediatric ALL patients and their association with decreased $\mathrm{BMD}^{\mathrm{LS}}$.

\section{Methods}

This study included one hundred and thirty Egyptian children who were newly diagnosed to have acute lymphoblastic leukemia (ALL). The study was approved by medical research ethical committee of our university hospitals during the period from January 2014 to December 2018. The study was done in the departments of pediatrics, clinical pathology, neurology, rheumatology, and radiodiagnosis. Assessments of the patients were performed twice: at inclusion into the current study (the first assessment) and after 3 years (the second assessment), but only one assessment (at the start of the study) was done for genotyping for all the participants in this study. Data of the patients who did not complete this study (20 patients were lost during follow-up and 10 patients died) were eliminated. So, this study included 100 patients (58 girls and 42 boys), "the patients' group." Patients' mean age/years $( \pm$ SD) were 11 years $( \pm 4)$. Patients with hormonal therapy or central nervous system irradiation were excluded. Other criteria for exclusion were allogeneic bone marrow transplantation or stem cell transplantation; patients with history of any serious gastrointestinal problems, malabsorption, and liver diseases; and those with concomitant medical diseases that may affect bone metabolism (hyperuricemia, syndrome of inappropriate secretion of antidiuretic hormone, type B lactic acidosis, non-islet cell tumor hypoglycemia, and hyperglycemia are other potential metabolic abnormalities occurring in patients with hematological malignancies) were also excluded from the study. None of our patients had history of neurological disorder prior to the onset of ALL.

One hundred apparently healthy Egyptian subjects, age and sex matched with the patients, were included as controls. Their mean age/years ( \pm standard deviation) were 10 years $( \pm 3.5)$; they were 57 girls and 43 boys. Informed consent was obtained from all subjects' parents or responsible relative before enrollment. Systematic assessment at inclusion into the study was done to identify the patients who had pre-existing low level of lumbar spine bone mineral density $\left(\mathrm{BMD}^{\mathrm{LS}}\right)$, levels of osteocalcin (OC), and alkaline phosphatase (ALP) \{specific markers of bone formation\} were also measured [15].

\section{Clinical examination}

All the patients were subjected to complete history taking, thorough general and neurological examination. Body mass index (BMI) percentiles were calculated and 
kids who measure at the 85th to 94th percentiles are considered overweight. A child whose BMI is between the 5th percentile and 85th percentile is in the healthy weight range. A child with a BMI below the 5th percentile is considered underweight [16]. The diagnosis of ALL was made by cytomorphological and immunological examination of blood and bone marrow smears of our local institution. For the diagnosis of ALL, 25\% blasts or more in the bone marrow was mandatory. Immunological markers were judged positive if expressed in $20 \%$ or more of the malignant cells. All cases were classified as precursor B-ALL. Data at inclusion of the patients into the current study were collected, including the address, sex, date of birth, age at disease onset, peripheral white blood cell (WBC) count, immunophenotyping, neurological examination, states of lymph nodes, liver, spleen, testes, bone marrow aspiration, \% blast cells at diagnosis, and bone marrow (BM) status at day 14 of induction, and according to these initial data, the eligibility criteria were put and the type of CCG protocol therapy was assigned (M1 marrow with blast count less than 5\%, M2 with blast count 5-25\%, and M3 marrow with blast count more than 25\%). Risk stratification was based on clinical data, morphological and immunological studies, day 14 bone marrow response, as well as conventional cytogenetic. Standard risk ALL group involved patients with age 1-9.99 years, WBC count $<50 \times 109 / 1$, and precursor B immunophenotype. High-risk standard arm group involved patients with age $\geq 10$ years and/or WBC $\geq 50 \times 109 /$ l. High-risk augmented arm group included patients with neurological disease and/or BM blast day14 > 5\% (slow early responders). Standard risk ALL patients were treated according to the CCG 1991 protocol6 using a single delayed intensification (DI) arm. The CCG 1991 protocol and high-risk patients received postinduction intensification therapy [17].

\section{Sample collection}

After an overnight fast, blood samples were taken from all children and were divided into three tubes:

1. The 1st K3-EDTA tube for osteocalcin determination: blood was centrifuged immediately and EDTAplasma was stored for 3 months at $-20^{\circ} \mathrm{C}$. Osteocalcin concentrations were determined by the electrochemiluminescence immunoassay using cobas e601 analyzer, normal range $6.6-35.7 \mathrm{ng} / \mathrm{ml}$.

2. The 2nd plain tube for total calcium, alkaline phosphatase, vitamin D (cutoff for normal value is $\geq 20 \mathrm{ng}$ / $\mathrm{ml}$ ), and parathyroid hormone: the total calcium and alkaline phosphatase were measured photometrically on cobas c 311/501 analyzer. Vitamin D and parathyroid hormone were assayed by the electrochemiluminescence immunoassay on cobas e601 immunoassay analyzer.

\section{Molecular analysis}

The 3rd EDTA tube for molecular assay of COLIA1 genotypes was according to manufacturer's instructions. The COLIA1 genotype measurement was done by digestion using restriction enzyme (Bal1) of DNA amplified by the polymerase chain reaction (PCR-RFLP) for all subjects at the start of the study.

\section{DNA extraction}

DNA was extracted from leukocytes of peripheral blood samples using the QIAamp ${ }^{\circ}$ UltraSens virus ${ }^{\circ}$ extraction kit (Qiagen) USA according to manufacturer protocol. The extracted DNA was stored at $-20^{\circ} \mathrm{C}$ until analysis.

\section{PCR amplification}

DNA was amplified using Maxime PCR PreMix Kit composed of Ready- to-Go PCR Beads which were designed and manufactured by iNtRON Biotechnology. PCR reaction with $25 \mu \mathrm{l}$ final volume was prepared by adding $12.5 \mu \mathrm{l}$ Master mix, $1.0 \mu \mathrm{l}$ forward primer, $1.0 \mu \mathrm{l}$ reverse primer, $10 \mu \mathrm{l}$ extracted DNA, and $0.5 \mu \mathrm{l}$ sterile high-quality water in PCR wells. PCR was done by the following conditions: initial denaturation at $94^{\circ} \mathrm{C}$ for 3 min, 35 cycles $\left(94{ }^{\circ} \mathrm{C}\right.$ for $50 \mathrm{~s}$ for denaturation, $62^{\circ} \mathrm{C}$ for10 $\mathrm{s}$ for annealing, and $72^{\circ} \mathrm{C}$ for $15 \mathrm{~s}$ for extension), and for final extension step $72^{\circ} \mathrm{C}$ for $5 \mathrm{~min}$. The PCR products were stored at $-80^{\circ} \mathrm{C}$ until used.

Collagen type I alpha-1gene primers: the primer sequences were as follows:

Forward primer: (5' GTCCAGCCCTCATCCTGGCC-3').

Reverse primer: (5'TAACTTCTGGACTATTTGCGGACTTTTTGG-3').

Detection of amplified PCR product by agarose gel electrophoresis: $5 \mu \mathrm{l}$ of each sample was slowly loaded into the sample well and $5 \mu \mathrm{l}$ PCR markers were also loaded into one of the wells. The power supply was programmed as $150 \mathrm{~V}$ and $100 \mathrm{~mA}$ for $20 \mathrm{~min}$ (Consort E 844). Then the gel was placed on the filter area of the ultraviolet transilluminator (Biometra). The amplified PCR product gave rise to $264 \mathrm{bp}$ fragment.

\section{Restriction digests reaction}

The amplified DNA was digested by using Bal 1 (Biolabs, USA, part No. R0534S, 250 units) 5,000 units/ml. Ten microliters of amplified product were added to $16 \mu \mathrm{l}$ sterile distilled water, $2 \mu \mathrm{l}$ of restriction enzyme, and $2 \mu \mathrm{l}$ of reaction buffer then incubated at $37^{\circ} \mathrm{C}$.

\section{Detection of the band of polymorphism}

The digested segments were subjected to electrophoresis on $8 \%$ non-denaturing polyacrylamide gel; the gel was stained using ethidium bromide $(1 \mathrm{mg} / \mathrm{ml})$ for $30 \mathrm{~min}$ at room temperature followed by visualization by the ultraviolet transilluminator. The amplified product $264 \mathrm{bp}$ 
fragment with Bal 1 restriction enzyme gave rise to the following:

- Undigested 264 bp fragment indicated the presence of $\mathrm{G}$ allele.

- Appearance of $246 \mathrm{bp}$ fragment indicated the presence of $T$ allele and identified as G-T substitution.

- -The homozygous variant $(G / G)$ results in one fragment at $264 \mathrm{bp}$, homozygous variant $(T / T)$ results in one fragment at $246 \mathrm{bp}$, while the heterozygous variant $(G / T)$ results in two fragments at $264 \mathrm{bp}$ and $246 \mathrm{bp}$.

Lumbar spine bone mineral density $\left(\mathrm{BMD}^{\mathrm{LS}}\right)$ was measured by dual-energy X-ray absorptiometry (DXA). Osteoporosis should be defined as a BMD ${ }^{\mathrm{LS}} \mathrm{Z}$ score lower than -2.0 and osteopenia as a condition in which the $\mathrm{Z}$ score lies between - 1.0 and -2.0 ISCD [18].

\section{Radiological evaluation}

Symptomatic fractures were confirmed by the plain Xray imaging. Patients presented with neurological complication were subjected to computer tomography with or without magnetic resonance imaging.

\section{Electrophysiological studies}

A patient who had clinical manifestations suggesting some neuromuscular disorders (neuropathy, radiculopathy, plexopathy or muscular affection) were subjected to motor and sensory nerve conduction studies. Electromyography was elicited according to the recommended protocols for diagnosis of different possible disorders. All tests were done by the same examiners using a Nicolet Viking Quest cart electrodiagnostic system. Extremity temperature was maintained at or above $30^{\circ} \mathrm{C}$ at time of examination. Any patient presented with seizures was subjected to electroencephalography (EEG) [19].

\section{Statistical analysis}

Presentation of quantitative data was done in the form of a mean ( \pm standard deviation) or median (range) in parametric and nonparametric data respectively. Qualitative data are represented in number and percentages. $t$ test was used in comparing two groups or Mann-Whitney $U$ test according to the type of data. ANOVA or Kruskal-Wallis test was used (according to the type of data; parametric or nonparametric respectively) for comparing more than two groups. Chi-squared test was done for comparing numerical data. Multivariate analysis as well as logistic regression analysis was used. All statistical analysis was performed using statistical program SPSS version 10 for Windows (SPSS, Chicago, IL, USA).

\section{Results}

Comparing the patients versus the controls at the start of the study (the first assessment) revealed that there was a significant decrement in osteocalcin $(\mathrm{OC})$ and alkaline phosphatase (ALP) levels as well as bone mineral density of the lumbar spine $\left(\mathrm{BMD}^{\mathrm{LS}}\right)$ of the pediatric ALL patients $(p=0.03,0.01$, and 0.01 respectively). As regards to COLIA1 gene polymorphism, "G/T" variants as well as "T" alleles were significantly more detected in the patients $(p=0.02$, $p=0.01$ ) as shown in Table 1 . There was a significant difference in OC and ALP levels and $\mathrm{BMD}^{\mathrm{LS}}$, between patients with COL1A1 polymorphism (G/T and $T / T$ variants) when compared versus those without polymorphism $(G / G$ variant) at the first assessment (Table 2). Immunophenotype and chromosomal abnormalities (numerical and structural) of patient group are shown in Fig. 1. In the patients, comparing the second assessment versus the first one, neurological complications were detected in 24 patients (4 of them had seizures, 10 had peripheral neuropathy, and lumbosacral radiculopathy was detected in 10 patients). Bone fractures were detected in 7 patients as shown in Table 2 . There was a significant decrease in $\operatorname{BMD}^{\mathrm{LS}}(p=0.01)$, OC, $(p=0.01)$, and ALP levels $(p=$ $0.04)$ as shown in Table 3 . There were significant differences among patients (with fractures versus those without fractures as well as those with neurological complications versus those without neurological complications) regarding $\mathrm{BMD}^{\mathrm{LS}}(p=0.04$ and 0.02 respectively), $\mathrm{OC}(p=0.02$ and 0.01 respectively), and ALP levels ( $p=0.03$ and 0.01 respectively). G/T and $\mathrm{T} / \mathrm{T}$ variants were significantly more detected in the fractured patients only $(p=0.01)$ as shown in Table 4. There was no significant difference between all patients' genotypes regarding the immunophenotype characteristics and chromosomal abnormalities (numerical and structural) as shown in Table 5. Doing multivariate analysis, $\mathrm{BMD}^{\mathrm{LS}}$ of the patients was significantly affected by neurological complications $(p=0.04)$, high-risk patients $(p=0.01)$, age (age $>10$ years at diagnosis) $(p=0.01)$, and COL1A1 "T" polymorphism $(p=0.03)$. Logistic regression analysis showed that COL1A1 "T" gene polymorphism is the most significant risk factor for decreased bone mineral density $(p=0.001)$ as shown in Tables 6 and 7.

\section{Discussion}

Acute lymphoblastic leukemia (ALL) is the most common malignancy in childhood. Since the survival is improved in ALL patients due to modern combined chemotherapy protocols, long-term complications increase as a result of intensive therapy [20]. Regarding to the first assessment of the patients compared to the controls, we found significant decrease in osteocalcin (OC) 
Table 1 Demographic and clinical characteristics of patients and controls at the start of the study (the first assessment)

\begin{tabular}{|c|c|c|c|c|c|}
\hline & & \multicolumn{2}{|c|}{ Patients (no. 100) } & Controls (no. 100) & $p$ value \\
\hline \multicolumn{2}{|l|}{ Sex (girls/boys) } & \multicolumn{2}{|c|}{$58(58 \%) / 42(42 \%)$} & $57(57 \%) / 43(43 \%)$ & 0.5 \\
\hline \multicolumn{2}{|l|}{ Age/year } & \multicolumn{2}{|c|}{$11( \pm 4)$} & $10( \pm 3.5)$ & 0.2 \\
\hline \multirow[t]{2}{*}{ Age } & $\leq 10$ years & \multicolumn{2}{|c|}{$40(40 \%)$} & $36(36 \%)$ & \multirow[t]{2}{*}{0.4} \\
\hline & $>10$ years & \multicolumn{2}{|c|}{$60(60 \%)$} & $64(64 \%)$ & \\
\hline \multicolumn{2}{|l|}{ BMI percentile } & \multicolumn{2}{|c|}{ 84th (70th-90th) } & 86th (68th-89th) & 0.1 \\
\hline \multicolumn{2}{|l|}{$\mathrm{BMD}^{\mathrm{LS}}$} & \multicolumn{2}{|c|}{$-1.9( \pm 0.44)$} & $-0.80( \pm 0.73)$ & $0.01^{*}$ \\
\hline \multirow[t]{2}{*}{ Risk groups } & High & \multicolumn{2}{|c|}{$45(45 \%)$} & - & \multirow[t]{2}{*}{-} \\
\hline & Standard & \multicolumn{2}{|c|}{$55(55 \%)$} & - & \\
\hline \multicolumn{2}{|c|}{ Parathormon (ng/l) } & \multicolumn{2}{|c|}{$45(10-56)$} & $50(12-60)$ & 0.8 \\
\hline \multicolumn{2}{|c|}{ Total calcium (mg/ml) } & \multicolumn{2}{|c|}{$9 \pm 0.9$} & $10 \pm 0.14$ & 0.2 \\
\hline \multicolumn{2}{|c|}{ Vitamin $\mathbf{D}(\mathrm{nmol} / \mathrm{l})$} & \multicolumn{2}{|c|}{$44(6-59)$} & $41(8-61)$ & 0.4 \\
\hline \multicolumn{2}{|c|}{ Osteocalcin (ng/ml) } & \multicolumn{2}{|c|}{$18(8-23)$} & $27(8-30)$ & $0.03^{*}$ \\
\hline \multicolumn{2}{|c|}{ Alkaline phosphatase $(U / L)$} & \multicolumn{2}{|c|}{$99(60-135)$} & $440(92-590)$ & $0.01^{*}$ \\
\hline \multirow[t]{5}{*}{ COLIA1 } & Genotypes & $\mathrm{G} / \mathrm{G}$ & $55(55 \%)$ & $72(72 \%)$ & 0.05 \\
\hline & & $\mathrm{G} / \mathrm{T}$ & $34(34 \%)^{*}$ & 19 (19\%) & $0.02^{*}$ \\
\hline & & $\mathrm{T} / \mathrm{T}$ & $11(11 \%)$ & $9(9 \%)$ & 0.5 \\
\hline & Alleles & G & $130(65 \%)$ & 180 (90\%) & 0.04 \\
\hline & & $\mathrm{T}$ & $70(35 \%)^{*}$ & 20 (10\%) & $0.01^{*}$ \\
\hline
\end{tabular}

$B M I$ body mass index, $B M D^{L S}$ bone mineral density of lumbar spine, COLIA1 collagen type 1alpha gene

*Significant

and alkaline phosphatase (ALP) levels and significant decrement in $\mathrm{BMD}^{\mathrm{LS}}$ of the entire patient's group compared to the controls. COL1A1 "GT" variants as well as " $T$ " allele were significantly more detected in the patient's group. This met with the findings of MostoufiMoab and Halton, who stated that osteocalcin and alkaline phosphatase were low in ALL patients at diagnosis [21]. Also, Gurney et al. reported altered bone mineralization and decreased bone formation prior to initiating therapy of all patients. At diagnosis markers of bone formation, osteocalcin, type I collagen carboxylterminal propeptide, and bone-specific alkaline phosphatase were low [22]. We also found COLIA1 "G/T" variants as well as " $\mathrm{T}$ " allele were significantly more detected in the patient's group, and $G / G$ variant as well as $G$ allele were significantly more detected in the control group. Mann et al. found the G/G genotype in $66.5 \%$ of ALL patients, G/T genotype in $33.02 \%$, and $T /$ $T$ genotype in $0.47 \%$ of them. GG genotype was more frequent in their control group (80.95\%) [23]. Also, Muszyñska et al. found that genotype distribution G/G genotype was detected in $33(80.5 \%)$ patients and $G / T$ genotype in 8 (19.5\%). They reported a significant difference between patient and control group [24]. In the present study, we found significant differences in OC and ALP levels as well as BMD ${ }^{\mathrm{LS}}$, between patients with COL1A1 polymorphism (G/T and $T / T$ variants) and those without polymorphism ( $G / G$ variant) at the first

Table 2 Comparing patient group $G / G$ variant versus $G / T$ and $T / T$ variants regarding laboratory data and $B M D^{L S}$ at diagnosis (the first assessment)

\begin{tabular}{|c|c|c|c|}
\hline & \multicolumn{2}{|l|}{ Patients (no. 100) } & \multirow{2}{*}{$\begin{array}{l}p \text { value } \\
0.5\end{array}$} \\
\hline & $\overline{\mathrm{G} / \mathrm{T} \text { and } \mathrm{T} / \mathrm{T}(45)}$ & G/G genotype (55) & \\
\hline Parathormon (ng/l) & $49(10-56)$ & $50(12-60)$ & 0.8 \\
\hline Total calcium (mg/ml) & $1 \pm 0.9$ & $10 \pm 0.14$ & 0.2 \\
\hline Vitamin D (nmol/l) & $44(6-59)$ & $41(8-61)$ & 0.4 \\
\hline Osteocalcin (ng/ml) & $12(10-21)$ & $23(9-23)$ & $0.03^{*}$ \\
\hline Alkaline phosphatase $(U / L)$ & $89(60-111)$ & $132(95-133)$ & $0.01^{*}$ \\
\hline $\mathrm{BMD}^{\mathrm{LS}}$ & $-2.00( \pm 0.49)$ & $-1.00( \pm 0.7)$ & $0.01^{*}$ \\
\hline
\end{tabular}

*Significant 


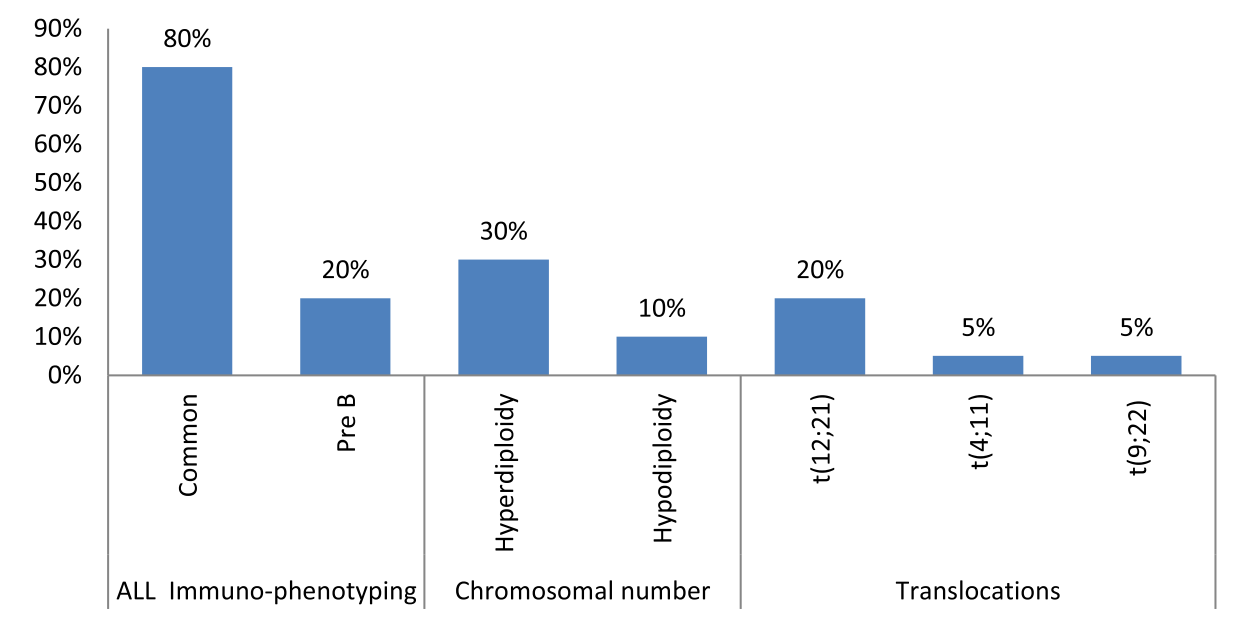

Fig. 1 Immunophenotypes and chromosomal abnormalities of acute lymphoblastic leukemia patients

assessment. Osteopontin is secreted by osteoclasts, osteocytes, and osteoblast. It is an important regulative component in fetal bone marrow hematopoietic stem cell and progenitor pools and is involved in progenitor differentiation and maintenance of hematopoietic stem cell quiescence. It plays pivotal roles in adult hematopoiesis, providing both a physical structure as well as interacting with hematopoietic and nonhematopoietic cellular and extracellular molecules of the hematopoietic stem cell niche [25]. Moreover, osteoclasts may take part not only in the regulation or maintenance, but also in the initial formation of the hematopoietic stem cell niche. In the absence of osteoclasts activity, the bone marrow hematopoietic stem cell niche formation is severely affected, leading to an impaired homing of these progenitors, thereby inhibiting the colonization of the bone marrow by hematopoietic stem cell [17]. In the 2nd assessment, we observed that neurological complications were detected in 24 patients (4 patients had seizures, 10 patients had peripheral neuropathy, and 10 patients had lumbosacral radiculopathy). Bone fractures were detected in 7 patients. There is a significant decrease in $\mathrm{BMD}^{\mathrm{LS}}$, osteocalcin, and alkaline phosphatase levels. This met with the findings of Baytan et al. who found that $7.1 \%$ of patients suffered from central nervous system (CNS) complications during the course of acute lymphoblastic leukemia treatment [26]. Intensified chemotherapy targets systemic disease, as well as tumor cells from the sanctuary sites especially the CNS. This entails usage of intrathecal therapy and high-dose systemic chemotherapy. This has also increased the incidence and severity of CNS complications [27]. Nazir et al. reported peripheral neuropathy in 19 out of 103 pediatric leukemic children [12]. Several types of mononeuropathies of individual nerves and plexus as well as lumbosacral radiculopathy have been also reported during

Table 3 Comparing clinical and laboratory data of the patients at diagnosis (first assessment) and after 3 years (second assessment)

\begin{tabular}{|c|c|c|c|}
\hline & \multicolumn{2}{|c|}{ Acute lymphoblastic leukemia patients } & \multirow[t]{2}{*}{$\boldsymbol{p}$ value } \\
\hline & First assessment & Second assessment & \\
\hline BMI percentile & 84th (70th-90th) & 86th (75th-91th) & 0.1 \\
\hline Neurological complications & - & seizures (4\%), peripheral neuropathy (10\%), lumbosacral radiculopathy (10\%) & - \\
\hline Fracture detection & - & $7(7 \%)^{*}$ & - \\
\hline $\mathrm{BMD}^{\mathrm{LS}}$ & $-1.9 \pm 0.44$ & $-2.654 \pm 0.11^{*}$ & $0.01^{*}$ \\
\hline Parathormon (ng/l) & $45(10-56)$ & $49(12-60)$ & 0.8 \\
\hline Total calcium (mg/dl) & $9 \pm 0.9$ & $10.8 \pm 0.20$ & 0.2 \\
\hline Vitamin D (nmol/l) & $44(6-59)$ & $40(12-55)$ & 0.2 \\
\hline Osteocalcin (ng/ml) & $18(9-23)$ & $13(-20)^{*}$ & $0.01^{*}$ \\
\hline Alkaline phosphatase $(\mathrm{U} / \mathrm{L})$ & $99(60-135)^{*}$ & $75(4-88)^{*}$ & $0.04^{*}$ \\
\hline
\end{tabular}


Table 4 Genetic and laboratory characteristics of the patients regarding the detection of fractures as well as neurological complications (during the second assessment)

\begin{tabular}{|c|c|c|c|c|c|c|c|}
\hline & & Fractures & & $p$ & Neurological & lications & $p$ value \\
\hline & & +ve $(n=7)$ & - ve $(n=93)$ & & +ve $(n=24)$ & -ve (76) & \\
\hline COLIA1 genotypes & $\mathbf{G} / \mathbf{G}(n=55)$ & 0 & 55 (59\%) & $0.01^{*}$ & $13(54 \%)$ & $42(55 \%)$ & 0.68 \\
\hline & $\mathbf{G} / \mathbf{T}(n=34)$ & $1(15 \%)$ & $33(35 \%)$ & & $8(33 \%)$ & $26(34 \%)$ & \\
\hline & $\mathbf{T} / \mathbf{T}(n=11)$ & $6(85 \%)$ & $5(5 \%)$ & & $3(12 \%)$ & $8(11 \%)$ & \\
\hline $\mathrm{BMD}^{\mathrm{LS}}$ & & $-2.00 \pm 0.44$ & $-1.00 \pm 0.11$ & $0.04^{*}$ & $-2.11 \pm 0.41$ & $-1.10 \pm 0.01$ & $0.02^{*}$ \\
\hline PTH $(n g / l)$, median & & $50(15-59)$ & $49(12-56)$ & 0.5 & $48(20-50)$ & $51(16-56)$ & 0.9 \\
\hline Vitamin D $(\mathrm{nmol} / \mathrm{l})$, & n (range) & $19(12-20)$ & $20(13-35)$ & 0.2 & $19(14-35)$ & $20(15-34)$ & 0.2 \\
\hline OC $(\mathrm{ng} / \mathrm{ml})$, median & & $8(8-12)$ & $13(9-20)$ & $0.02^{*}$ & $10(8-20)$ & $18(10-19)$ & $0.01^{*}$ \\
\hline ALP $(U / L)$, median ( & & $45(45-87)$ & $76(50-84)$ & $0.03^{*}$ & $50(45-80)$ & $80(46-88)$ & $0.01^{*}$ \\
\hline
\end{tabular}

*Significant

$B M D^{L S}$ bone mineral density of lumbar spine, $P T H$ parathormon, $O C$ osteocalcin, $A L P$ alkaline phosphatase

leukemic patient's treatment $[11,28]$. Regarding to the detection of fractures as well as neurological complications (during the second assessment) in the patients of the present study, a significant difference was detected in $\mathrm{BMD}^{\mathrm{LS}}, \mathrm{OC}$, and ALP levels in the fractured patients as well as those with neurological complications. G/T and $T / T$ variants were significantly more detected in the fractured patients only. Mostoufi-Moab and Halton reported that fracture in long bones and vertebrae after treatment in ALL patients. They reported that the incidence of nonpathologic fractures in ALL patients during treatment varies from 12 to $39 \%$ [21]. Gurney et al. observed the improvement of $\mathrm{BMD}^{\mathrm{LS}}$ after cessation of ALL therapy, but it was significantly lower in comparison to healthy children [22]. Also, Wasilewski-Masker et al. reported decreased bone mass: at diagnosis, during treatment, and post-treatment [29]. MuszyñskaRosan et al. agreed with us that there was a significant negative impact of the $G T$ genotype on $\mathrm{BMD}^{\mathrm{LS}}$ [24]. This met also with the findings of two previous studies, both found that polymorphism of Sp1 binding site of the COLIA1 gene was associated with low bone mineral density and fracture detection [29, 30]. In the present study, there was no significant relation between the COLIA1 genotype variants and the occurrence of the neurological complications. One previous study found a significant association between the COL1A1 gene polymorphism and arterial compliance that may attribute to the development and progression of atherosclerosis and increased cardiovascular risk but in older age group than patients of the present study [5]. Moreover, chromosomal abnormalities (numerical and structural) of patients in the present study did not show any significant difference regarding neither COLIA1 genotype variants nor the other assessment parameters. Doing multivariate analysis, $\mathrm{BMD}^{\mathrm{LS}}$ of patients was significantly affected by the detection of the neurological complications, high risk stratification, and age more than 10 years at diagnosis as well as COL1A1 "T" allele. By logistic regression analysis, we found that

Table 5 Genetic and laboratory characteristics of the patients regarding the immunophenotype characteristics and chromosomal abnormalities (numerical and structural) in ALL patients (during the second assessment)

\begin{tabular}{|c|c|c|c|c|c|c|c|c|c|}
\hline \multirow[t]{2}{*}{$\mathrm{NO}$} & \multicolumn{2}{|c|}{ Immunophenotyping } & \multirow[t]{2}{*}{$p$} & \multicolumn{2}{|c|}{ Numerical abnormalities } & \multirow[t]{2}{*}{$p$} & \multicolumn{2}{|c|}{ Structural abnormalities } & \multirow[t]{2}{*}{$p$} \\
\hline & $\begin{array}{l}\text { Common } \\
80\end{array}$ & $\begin{array}{l}\text { Pre b } \\
20\end{array}$ & & $\begin{array}{l}+v e \\
40\end{array}$ & $\begin{array}{l}-v e \\
60\end{array}$ & & $\begin{array}{l}+v e \\
60\end{array}$ & $\begin{array}{l}-v e \\
40\end{array}$ & \\
\hline G/G genotype & 44 & 11 & 0.6 & 22 & 33 & 0.91 & 31 & 22 & 0.91 \\
\hline$G / T$ genotype & 26 & 8 & & 13 & 21 & & 21 & 13 & \\
\hline$T / T$ genotype & 10 & 1 & & 5 & 6 & & 8 & 5 & \\
\hline $\mathrm{BMD}^{\mathrm{LS}}$ & $-2.00 \pm 0.44$ & $-2.0 \pm 0.11$ & 0.4 & $-2.11 \pm 0.41$ & $-1.1 \pm 0.01$ & 0.2 & $-2.0 \pm 0.44$ & $-2.1 \pm 0.48$ & 0.6 \\
\hline PTH (ng/l), median (range) & $46(12-58)$ & $49(20-60)$ & 0.5 & $48(19-56)$ & $50(12-56)$ & 0.9 & $50(12-60)$ & $53(13-58)$ & 0.4 \\
\hline Vit. D (nmol/l), median (range) & $20(12-35)$ & $22(15-30)$ & 0.2 & $19(14-31)$ & $21(13-35)$ & 0.2 & $22(14-34)$ & 19 (12-35) & 0.3 \\
\hline OC $(\mathrm{ng} / \mathrm{ml})$, median (range) & $8(8-20)$ & $10(9-18)$ & 0.2 & $16(8-18)$ & $18(9-20)$ & 0.1 & $18(8-17)$ & $20(14-20)$ & 0.3 \\
\hline ALP (U/L), median (range) & $71(45-88)$ & $67(50-82)$ & 0.3 & $65(47-82)$ & $69(45-88)$ & 0.1 & $73(46-88)$ & $70(62-83)$ & 0.2 \\
\hline
\end{tabular}

$B M D^{L S}$ bone mineral density of lumbar spine, $P T H$ parathormon, Vit. $D$ vitamin $D, O C$ osteocalcin, $A L P$ alkaline phosphatase 
Table 6 Multivariate analyses of different risk factors affecting bone mineral density of lumbar spine (BMD ${ }^{L S}$ ) in acute lymphoblastic leukemia patients after 3 years (the second assessment)

\begin{tabular}{|c|c|c|c|c|}
\hline Risk factors & Population & $\mathrm{BMD}^{\mathrm{LS}}$ & OR $[95 \% \mathrm{Cl}]$ & $p$ value \\
\hline \multirow[t]{2}{*}{ Sex } & Girls (58\%) & $1.336 \pm 0.44$ & $5.5[0.2-8.7]$ & 0.5 \\
\hline & Boys (42\%) & $1.356 \pm 0.64$ & & \\
\hline \multirow[t]{2}{*}{ BMI percentile } & $>85^{\text {th }}(55 \%)$ & $1.735 \pm 0.14$ & $3.9[0.12-8.97]$ & 0.6 \\
\hline & $\leq 85^{\text {th }} 10(45 \%)$ & $1.04 \pm 0.24$ & & \\
\hline \multirow[t]{2}{*}{ Neurological complications } & Detected (24\%) & $2.13 \pm 0.60$ & 9.9 [10.2-13.3] & $0.04^{*}$ \\
\hline & Not detected (76\%) & $1.29 \pm .002$ & & \\
\hline \multirow[t]{2}{*}{ Risk groups } & High risk (45\%) & $2.931 \pm 0.60$ & $6.1[10.2-13.3]$ & $0.01^{*}$ \\
\hline & Standard risk (55\%) & 1. $690 \pm 0.11$ & & \\
\hline \multirow[t]{2}{*}{ Age at diagnosis } & $>10$ years $(60 \%)$ & $2.28 \pm 0.06$ & 5.9 [13.9-14.67] & $0.01 *$ \\
\hline & $\leq 10$ years $(40 \%)$ & $1.06 \pm 0.44$ & & \\
\hline \multirow[t]{2}{*}{ COLIA1 (alleles) } & T (35\%) & $2.645 \pm 0.91$ & $5.5[11.9-22.1]$ & $0.03^{*}$ \\
\hline & G (65\%) & $0.947 \pm 0.13$ & & \\
\hline
\end{tabular}

$\mathrm{BMD}^{\mathrm{LS}}$ bone mineral density of lumbar spine, BMI body mass index, COLIA1 collagen type 1 alpha gene

COLIA1 "T" allele was the most significant risk factor. In the context of our findings, Mann et al. reported that COLIA1 allele should be considered as an additional negative element of the bone structure in children, especially when another factor is present (high-risk group) [23]. Mostoufi-Moab et al. agreed that during ALL therapy, the older the age of the patients at diagnosis (years), the more the significant decline of $\mathrm{BMD}^{\mathrm{LS}}$ [21]. Moreover, a polymorphism in the Sp1 binding site of the COLIA1 gene showed a significant association with bone complications in ALL patients [21]. Another study found that the polymorphism of " $\mathrm{T}$ " allele in the Sp1 binding site of the COLIA1 gene in epileptic patients was related to lower BMD ${ }^{\mathrm{LS}}[30]$.

Epilepsy and antiepileptic drugs have been identified as independent risk factors for lower $\mathrm{BMD}^{\mathrm{LS}}$ [31-33]. Also, Kim et al. found that stroke patients had decreased $\mathrm{BMD}^{\mathrm{LS}}$ during different periods of the rehabilitation stage [34]. Authors of the present study found that the COLIA1 "T" allele was the most significant risk factor. This met with the findings of Muszyñska-Rosan et al., who reported a significant negative impact of the $G / T$ genotype on $\mathrm{BMD}^{\mathrm{LS}}$ [24].

Table 7 Logistic regression analysis of different risk factors affecting bone mineral density of lumbar spine $\left(B M D^{L S}\right)$ in acute lymphoblastic leukemia patients after 3 years (the second assessment)

\begin{tabular}{lll}
\hline & OR [95\% Cl] & $\boldsymbol{p}$ value \\
\hline COLIA1 (T alleles) & $2.6[9.8-13.6]$ & $0.001^{*}$ \\
Neurological complications & $4.5[12.3-13.1]$ & 0.05 \\
Age at diagnosis & $6.5[10.5-13.2]$ & 0.05 \\
\hline
\end{tabular}

COLIA1 collagen type 1 alpha gene

*The most significant

\section{Conclusion}

COLIA1 gene polymorphism, decreased $\mathrm{BMD}^{\mathrm{LS}}$, and neurological complications were significantly detected in pediatric ALL patients. COLIA1 gene polymorphism is a significant risk factor for decreased $\mathrm{BMD}^{\mathrm{LS}}$ in pediatric ALL patients. There is no significant relation between COLIA1 gene polymorphism and the development of neurologic complications.

\section{Recommendation}

Further longitudinal studies on a wider scale and larger number of patients are recommended for the development of new specific treatment strategies regarding the findings of the present study.

\section{Abbreviations}

ALL: Acute lymphoblastic leukemia; ALP: Alkaline phosphatase; BM: Bone marrow; BMD ${ }^{\text {LS }}$ : Lumbar spine bone mineral density; BMl: Body mass index; CNS: Central nervous system; COL1A1: Collagen type I alpha 1; DXA: Dualenergy X-ray absorptiometry; EEG: Electroencephalography; WBC: White blood cell; OC: Osteocalcin

\section{Acknowledgements}

To all members included to this research.

\section{Authors' contributions}

$A O, R N, M Y, G N, Y M, A A, M A, T A$, and HE carried out the work. AO and RN designed the study. MY, YM, and MA coordinated the research team. RN, AA, and MA collected the patients and gathered the clinical data. RN, MY, and YM had collected the data. AO and HE did the laboratory work of the study and improvised the manuscript for intellectual content. TA had done the imaging work. All authors were involved in drafting the article or revising it critically for important intellectual content, and all authors approved the final version to be published.

Funding

There is no body responsible for funding of this study.

Availability of data and materials

Not applicable 


\section{Ethics approval and consent to participate}

This study was approved by the ethical committee of university hospitals; committee's reference number is ZA-IRB \#4231/8-1-2014, and the approved date is $8 / 1 / 2014$.

We described the aim of this research to subjects' parents or responsible relative shared in this research before enrollment and they gave verbal consent but refuse to write consent, and ethics committee approved this procedure.

\section{Consent for publication}

Not applicable

\section{Competing interests}

The authors do not have any conflict of interest.

\section{Author details}

'Department of Clinical Pathology, Faculty of Medicine, Zagazig University, Zagazig, Egypt. ${ }^{2}$ Department of Neurology, Faculty of Medicine, Zagazig University, Zagazig, Egypt. ${ }^{3}$ Department of Rheumatology \& Rehabilitation, Faculty of Medicine, Zagazig University, Zagazig, Egypt. ${ }^{4}$ Department of Pediatric, Faculty of Medicine, Zagazig University, Zagazig, Egypt. ${ }^{5}$ Department of Radiodiagnosis, Faculty of Medicine, Zagazig University, Zagazig, Egypt.

\section{Received: 12 November 2019 Accepted: 13 July 2020}

Published online: 09 October 2020

\section{References}

1. Sun LR, Cooper S (2018) Neurological complications of the treatment of pediatric neoplastic disorders. Pediatr Neurol 85:33-42

2. Erdem M, Tüfekçi1 Ö, Kızıldağ S, Yılmaz Ş, Kızmazoğlu D, et al. (2019). Investigation of the relationship between Fok1 and COL1A1 gene polymorphisms and development of treatment-related bone complications in children with acute lymphoblastic leukemia. Turk J Hematol 36:12-18.

3. Meena MC, Hemal A, Satija M, Arora SK, Bano S. (2015). Comparison of bone mineral density in thalassemia major patients with healthy controls. Advances in Hematology; 4.

4. Rizzoli R, Body JJ, Brandi ML, Cannata-Andia J, Chappard D, El Maghraoui A (2013) Cancer-associated bone disease. Osteoporos Int 24(12):2929-2953

5. Brull DJ, Murray LJ, Boreham CA, Ralston SH, Montgomery HE, Gallagher AM et al (2001) Effect of a COL1A1 Sp1 binding site polymorphism on arterial pulse wave velocity an index of compliance. Hypertension. 38:444-448

6. Van Pottelbergh I, Goemaere S, Nuytinck L, De Peape A, Kaufman J (2001) Association of the type I collagen alpha1 Sp1 polymorphism, bone density and upper limb muscle strength in community-dwelling elderly men. Osteoporosis. 12:895-901

7. Yoneyama $\mathrm{T}$, Kasuya $\mathrm{H}$, Onda $\mathrm{H}$, Akagawa $\mathrm{H}$, Hashiguchi $\mathrm{K}$, Nakajima $\mathrm{T}$ et al (2004) Collagen type I_2 (COL1A2) is the susceptible gene for intracranial aneurysms. Stroke. 35:443-448

8. Lindahl K, Rubin C, Brandstrom H (2009) Heterozygosity for a coding SNP in COL1A2 confers a lower BMD and an increased stroke risk. Biochem Biophys Res Commun 384:501-505

9. John S, Jehi L, Manno EM, Conway DS, Uchino K (2015) COL4A1 gene mutation - beyond a vascular syndrome. Seizure. 31:19-21

10. Durrani-Kolarik S, Manickam K, Chen B (2017) COL4A1 Mutation in a neonate with intrauterine stroke and anterior segment dysgenesis. Pediatr Neurol 66:100-103

11. Arpaci T, OzgurA AT, Arpaci R, Karagun B, Ugurluer G (2017) Magnetic resonance imaging of neurologic complications through the treatment of childhood leukemia and lymphoma. Can Assoc Radiol J 68(2):98-105

12. Nazir HF, AlFutaisi A, Zacharia M, Elshinawy M, Mevada ST, Alrawas A et al (2017) Vincristine-induced neuropathy in pediatric patients with acute lymphoblastic leukemia in Oman: frequent autonomic and more severe cranial nerve involvement. Pediatr Blood Cancer 64(12)

13. Vagace JM, de la Maya MD, Caceres-Marzal C, Gonzalez de Murillo S, Gervasini G (2012) Central nervous system chemotoxicity during treatment of pediatric acute lymphoblastic leukemia/lymphoma. Crit Rev Oncol Hematol 84(2):274-286

14. Oleson CV (2017) Osteoporosis in stroke and seizure disorders. Osteoporosis Rehabil:111-131. https://doi.org/10.1007/978-3-319-45084-1_8
15. Siviero-Miachon AA, Spinola-Castro AM, de Martino Lee ML, Calixto AR, Geloneze B, Lazaretti-Castro M et al (2017) Visfatin is a positive predictor of bone mineral density in young survivors of acute lymphocytic leukemia. J Bone Miner Metab 35(1):73-82

16. Nihiser AJ, Lee SM, Wechsler $\mathrm{H}$ et al (2007) Body mass index measurement in schools. J Sch Health 77(10):651-671

17. O'Brien MM and Lacayo NJ. Acute leukemia in children Conn's Current Therapy 2008. Section 6. p. 446-453.

18. Crabtree NJ, Arabi A, Bachrach LK et al (2014) Dual-energy X-ray absorptiometry interpretation and reporting in children and adolescents: the revised 2013 ISCD Pediatric Official Positions. J Clin Densitom 17:225242

19. Preston DC, Shapiro BE (2012) Electromyography and neuromuscular disorders: clinical-electrophysiological correlations. 3rd edit

20. Donmez AD, Isik P, Cetinkaya S, Yarali N (2019) Bone loss in pediatric survivors of acute lymphoblastic. Leukemia Eurasian J Med 51(1):38-41

21. Mostoufi-Moab S, Halton J (2014) Bone morbidity in childhood leukemia: epidemiology, mechanisms, diagnosis, and treatment. Curr Osteoporos Rep 12(3):300-312

22. Gurney JG, Kaste SC, Liu W, Srivastava DK, Chemaitilly W, Ness KK et al (2014) Bone mineral density among long-term survivors of childhood acute lymphoblastic leukemia: results from the St. Jude Lifetime Cohort Study. Pediatr Blood Cancer 61(7):1270-1276

23. Mann V, Ralston SH (2003) Meta-analysis of COL1A1 Sp1 polymorphism in relation to bone mineral density and osteoporotic fracture. Bone. 32(6):711717

24. Muszyñska-Roslan K, Galicka A, Sawicka M, Krawczuk-Rybak M (2004) Association of collagen type I a1 gene polymorphism with bone density in survivors of childhood cancer - preliminary report. Rocz Akad Med Bialymst 49(1):46-48

25. Cao H, Cao B, Heazlewood CK, Domingues M, Sun X, Debele E, McGregor NE, Sims NA, Heazlewood SY, Nilsson SK (2019) Osteopontin is an important regulative component of the fetal bone marrow hematopoietic stem cell niche. Cells. 8:985

26. Baytan B, Evim MS, Güler S, Güneş AM, Okan M (2015) Acute central nervous system complications in pediatric acute lymphoblastic leukemia. Pediatr Neurol 53:312-318

27. Mandal P, Sahi PK, Meena P, Verma D, Jain A, Singh V, Chandra J (2016) CNS complications during treatment of acute lymphoblastic leukemia/ lymphoblastic lymphoma. Pediatric Hematology Oncology. Journal. 1:S1S33

28. Grisold W, Grisold A, Hainfellner J, Meng S, Maros C (2014) Leukemia and the peripheral nervous system: a review. J Leuk 2:162

29. Wasilewski-Masker K, Kaste SC, Hudson MM, Esiashvili N, Mattano LA, Meacham LR (2008) Bone mineral density deficits in survivors of childhood cancer: long-term follow-up guidelines and review of the literature. Pediatrics. 121(3):e705-e713

30. Te Winkel ML, van Beek RD, de Muinck Keizer-Schrama SM et al (2010) Pharmacogenetic risk factors for altered bone mineral density and body composition in pediatric acute lymphoblastic leukemia. Haematologica. 95(5):752-759

31. Villegas-Martínez I, de-Miguel-Elízaga I, Carrasco-Torres R, Marras C, CanterasJordana M, Yedra-Guzmán MJ et al (2016) The COL1A1 SP1 polymorphism is associated with lower bone mineral density in patients treated with valproic acid. Pharmacogenet Genomics 26(3):126-132

32. Singla S, Kaushal S, Arora S, Singh G (2017) Bone health in patients with epilepsy: a community-based pilot nested case-control study. Ann Indian Acad Neurol 20(4):367-371

33. Inaloo S, Paktinat $M$, Saki F, Katibeh $P$, Nemati $H$, Dabbaghmanesh $M$, Omrani G (2019) Bone mineral density loss in ambulatory children with epilepsy in spite of using supplemental vitamin D in Southern Iran: a casecontrol study. J Bone Miner Metab 37(3):537-544

34. Kim HD, Kim SH, Kim DK, Jeong HJ, Sim YJ, Kim GC (2016) Change of bone mineral density and relationship to clinical parameters in male stroke patients. Ann Rehabil Med 40(6):981-988

\section{Publisher's Note}

Springer Nature remains neutral with regard to jurisdictional claims in published maps and institutional affiliations. 